\title{
Effect of Social Media on Medical College Student's Behaviour in
}

\section{Chennai}

\author{
Vijayasankari A* , Kalpana S, Srinivas G \\ Department of Epidemiology. The Tamilnadu Dr.M.G.R Medical University, Chennai
}

*Corresponding Author: Vijayasankari A, Department of Epidemiology. The Tamilnadu Dr.M.G.R Medical University, Chennai. E-mail: vijayasankarisasikumar@gmail.com

Received Date: July 08, 2020; Accepted Date: August 04, 2020; Published Date; August 11, 2020.

Citation: Vijayasankari A, Effect of Social Media on Medical College Student's Behaviour in Chennai, J. Psychology and Mental Health Care.4(4). Doi: $10.31579 / 2637-8892 / 089$

Copyright: () 2020 Vijayasankari A, This is an open-access article distributed under the terms of the Creative Commons Attribution License, which permits unrestricted use, distribution, and reproduction in any medium,provided the original author and source are credited.

\begin{abstract}
:
Background: Social networks include websites and applications that allow users to share content, ideas, opinions, beliefs, feelings, and personal, social, and educational experiences. Thus, considering the key role of students in promoting the quality of physical and mental health of society, and also due to the lack of knowledge on the type of relationship between social networking addiction and academic performance of the students of medical sciences, the present study was designed and implemented. The purpose of this study was to investigate the effect of social media among the students of medical sciences and their behaviour changes.

Methods: This cross-sectional study was conducted among medical students. Stratified random sampling was used. The study tools included personal information form and the Bergen Social Media Addiction Scale. Data were analyzed using SPSS-18.0.

Results: Most of the students are using social media for studies and to talk with their friends and whenever they feel alone.

Conclusion: Over all the social media use age was moderate. Overall, social media appeared to be very useful tool for students' community as they use them to improve their studies and carrier development. However, their negative effects seemed to be very poor as compared to their positive effects.
\end{abstract}

Keywords: social media; medical students; behaviour; mobile phone; social network

\section{Introduction:}

Social media, defined as interactive Web applications have been on the rise globally, particularly among adults [1]. Social media is an omnipresent part of everyday life. It provides users with an easy way to engage and connect with others without meeting face-to-face. This form of communication provides a lot of opportunity for companies and individuals to reach a massive audience [2]. In 21 st century, Social media networks are one in every of the foremost commonly used communication methods everywhere the world. Social media are growing rapidly among the younger generation altogether over the world. Internet plays a big role in student's life. Students use the online facility for various purposes. While it's definitely true that social media allows people to pursue interpersonal relationships with distant friends and family, it can even have a negative impact on people's lives. Some people will use various social media applications to network career opportunities, find people across the globe with like interests, and share their thought, feelings, insight, and emotions. the power of social media is that the power to connect and share messages or information with anyone on Earth, or with many folks simultaneously. There are two types of social media users; digital natives and digital immigrants. Digital natives are the ones who were born after 1980, they came to this world when the digital media existed. However, digital immigrants are the ones who were born before 1980 and adapted their lives to digital media [3] More than 4.5 billion people now use the internet, while social media users have passed the 3.8 billion mark [4] Nearly 90 percent of people between the ages of 18 and 29 used a minimum of 1 style of social media. Their use in numerous fields has been examined in several research studies. The aim of the study is to seem at the influence and effects of social media on college student's behavior and also to identify the positive and negative effects of social media among college students. Research has shown that individuals who use social media frequently have increased levels of negative emotions like envy and isolation. How does this happen? The younger generation is that the people who will lead our world within the longer term, must be educated so as that they're going to have an effect on the world which India becomes a far better country. College students widely engaged in using Social Media. So, they'll affect a student's personal and professional lives. Thus, this study is meant to hunt out out the positive and negative effects of social media on college students in Chennai. Social Media is that the interaction among people during which they create, share, or exchange information and concepts in virtual communication and networks. Social media can even be said to be a gaggle of internet-based applications that hinge upon the ideological and technological foundations of the online that allows the creation and exchange of usergenerated content. It's a platform to form social networks or social relations among people. The foremost popular online trend of the previous couple of years. Not only do social media sites provide the way to stay connected with friends, but they'll also offer opportunities for professional online networking. Hence, this study was undertaken to find the effect of social media on college students behaviours in Chennai city.

\section{Methods}

The descriptive cross-sectional study was done among the health science female students studying in affiliated colleges of the Tamilnadu Dr.M.G.R.Medical University in Chennai city. A sample size of 363 
students were included within the study. The convenient sampling method was accustomed recruit the samples within the study. A Structured Questionnaire was used to obtain data after explaining them about the study. consent was obtained from the participants. Likert type scale questionnaire was used to assess their behavior on social media. Twenty questions were asked about social media usage and its effect. All the data were entered in SPSS ver.24. The analysis of the data was planned supported the target of the study. Both descriptive and inferential statistics were used for data analysis and interpretations. Score was give as strongly disagree to [1-5] strongly agree. Effect score of less than 2 was considered as mild, 3 was considered as moderate and more than 3 was considered as severe. Mean score for each question were calculated the data obtained were tabulated, organized and analysed supported the objectives of the study using descriptive statistics. The research included mainly access to records was performed with prior permission of the appropriate authorities.

\section{Results}

A total of 363 medical students were interviewed in the study. All the participants are women. The majority of the participants were between 22-25 years and the mean age was 23 years.

\begin{tabular}{|c|c|c|}
\hline Questions & Mean Score & SD \\
\hline I am eager to go on Social Media (SM) & 2.90 & 1.36 \\
\hline I look for internet connectivity everywhere so as to go on SM & 2.61 & 1.31 \\
\hline Going on SM is the first thing I do when I wake up in the morning & 2.35 & 1.30 \\
\hline I see SM as an escape from the real world & 2.93 & 3.30 \\
\hline A life without SM becomes meaningless for me & 2.23 & 1.37 \\
\hline I prefer to use SM even there are somebody around me & 2.42 & 1.27 \\
\hline I prefer the friendships on SM to the friendships in the real life & 4.37 & 1.19 \\
\hline I express myself better to the people with whom I get in contact on SM & 2.36 & 1.19 \\
\hline I usually prefer to communicate with people via SM & 2.66 & 1.21 \\
\hline I want to spend time on SM when I am alone & 4.10 & 1.50 \\
\hline I pass over my homework because I spend much time on SM & 2.41 & 1.30 \\
\hline I feel unhappy when I am not on SM & 2.49 & 1.30 \\
\hline I do not even think of my studies when I am on SM & 2.45 & 1.36 \\
\hline I do not even notice that I am hungry or thirsty When I am on SM & 2.33 & 1.36 \\
\hline I notice that my productivity has diminished due to SM & 2.67 & 1.29 \\
\hline I am not spending much time with my family members due to SM & 2.63 & 1.30 \\
\hline I have physical problems because of SM use & 2.71 & 1.26 \\
\hline I always on SM to share my day to day activity with friends/relatives & 3.01 & 1.13 \\
\hline $\begin{array}{l}\text { I use SM mainly to see related to my studies/course that makes me always stay on } \\
\text { SM }\end{array}$ & 4.21 & 1.40 \\
\hline I do not use SM for my carrier development related activity & 2.60 & 1.40 \\
\hline
\end{tabular}

Table 1: The table shows that the mean score and the standard deviation of the variables.

This study findings shows that, they are spending more time on social media when they are alone. Also they often use it to talk with their friends and for their studies.

\section{Discussion}

The study findings showed that how social media is being used by medical students. They used social media to refer study material, and to speak with their friends. Mainly they use these social media whenever they feel alone. Based on the findings we realized that students are conversant and familiar with social media most importantly social network. Just as Gurcan et al study, [5] "social media zips through our campuses" somewhere in the literature, Social network has dominated with regards to the use of social media among students. Social media has become a significant factor in many young person's day to day routine. On an academic level, social media can have a negative effect on student productivity when it comes to concentration in the classroom, timekeeping, and conscientiousness. Its important to discuss ways to combat these factors without heralding new media as a societal 
crime which many previous attempts of raising awareness on this issue have tended to do. It is without a doubt that platforms such as Facebook, Twitter, and Instagram have introduced many beneficial aspects to modern day society and its users [6]. Social media is rapidly changing the communication setting of today's social world. The emergent of social media is significantly influencing the academic life of students. Institutions and academician are continually trying with social media technologies hoping to excite critical thinking skills, collaboration, and knowledge construction. Today social media has been accepted by higher institution making it a platform where students connect with their instructors, fellow students and other higher authorities across the board. The study done by seyyed et al showed that he mean social networking addiction was higher in male students $(52.65 \pm 11.50)$ than in female students $(49.35 \pm 13.96)$ and this difference was statistically significant $(P<0.01)$. There was a negative and significant relationship between students' addiction to social networking and their academic performance $(\mathrm{r}=-0.210, p<0.01)$ but the present study was done only with women so we cannot compare out findings with the seyyed et al study [7]. The results of a meta-analysis study (2018) on internet addiction showed that, the prevalence of internet addiction among medical students was $30.1 \%$ worldwide [8]. Results of a meta-analysis study (2017) suggest that, the prevalence of internet addiction in Iran is moderate. Social networking addiction increases the incidence of disorders such as depression, stress and anxiety $[9,10,11]$.The use of social networks has become an integral part of the lives of many students, because they introduce them to a world of different possibilities, especially in their field of study. However, these networks are like double-edged knives. If students do not manage the use of these networks, they will be addicted to them, and will have to face different consequences, especially in relation to their education.

\section{Conclusion}

The level of social networking addiction of the students was moderate, in this study. Overall, social media appeared to be a very useful tool for students community as they use them to improve their studies and carrier development. In other words, social media seemed to be modern tools of learning. However, their negative effects seemed to be very poor as compared to their positive effects. It is suggested that the lecturers, faculties and others social media users, especially Facebook pages owners, disseminate advantageous issues which help students in terms of enhancing their knowledge and information. It shows that they should not be addiction to social networking sites are a problematic issue which affects the student's life. Hence, We should not leave them alone for long time.

\section{Limitations}

This study had several limitations. Due to the cross-sectional nature of this study, it was not possible to explain the causal relationships between the variables of social networking addiction and academic performance of students. In the current study, the data were collected by self-reporting method that too with only women that could have affected the accuracy of the results and gender bias. However, the researcher tried to solve this limitation by reassuring the participants that their responses would remain confidential.

\section{References:}

1. Zyoud SH, Sweileh WM, Awang R, Al-Jabi SW. (2018). Global trends in research related to social media in psychology: mapping and bibliometric analysis. International Journal of Mental Health Systems.12(1):4.

2. (2020). The use of social media and its impact for research:: BioResources [Internet].

3. Hashem Y.(2015). The Impact of Social Media on the Academic Development of School Students. International Journal of Business Administration. 1;6:46.

4. Digital 2020: 3.8 billion people use social media [Internet]. We Are Social. 2020

5. Gurcan, H. I. (2015). Contribution of Social Media to the Students' Academic Development. International Journal of Information and Education Technology, 5(12), 965.

6. Education \& Learning, Education News \& Views, In the Classroom. (2018). The Effects Of Social Media In Student Teens

7. Azizi, S.M., Soroush, A. and Khatony, A. (2019). The relationship between social networking addiction and academic performance in Iranian students of medical sciences: a cross-sectional study. $B M C$ Psychol 7, 28

8. Zhang MW, Lim RB, Lee C, Ho RC. (2018). Prevalence of internet addiction in medical students: a meta-analysis. Acad Psychiatry:;42(1):88-93

9. Modara F, Rezaee-Nour J, Sayehmiri N, Maleki F, Aghakhani N, et al. (2017). Prevalence of internet addiction in Iran: a systematic review and meta-analysis. Addiction \& health.;9(4):243.

10. Tang CS-k, Koh YYW. (2017). Online social networking addiction among college students in Singapore: comorbidity with behavioral addiction and affective disorder. Asian J Psychiatr;25:175-178.

11. Brailovskaia J, Margraf J. (2017). Facebook addiction disorder (FAD) among German students - a longitudinal approach. PLoS One.;12(12):e0189719. 